\title{
IRT Kerajinan Tangan Clay Oleh-Oleh Khas Bali
}

\author{
${ }^{1}$ Ni Wayan Setiasih, ${ }^{2}$ Gede Herdian Setiawan \\ Institut Teknologi dan Bisnis STIKOM Bali ${ }^{1,2}$ \\ Email: setiasih@stikom-bali.ac.id
}

\begin{abstract}
ABSTRAK
Clay adalah handcraft (kerajinan tangan) bernilai seni tinggi yang mudah dibentuk dengan tangan. Ni Ketut Indrawati,S.sn (Mitra) sebagai penggiat seni berusaha menggali potensi pada bidang industri kreatif oleh-oleh khas Bali dengan menciptakan produk oleh-oleh yang menarik, memiliki khas Bali dan dengan harga yang terjangkau. Mitra melakukan inovasi kerajinan tangan berbahan dasar tepung yang sering di sebut dengan Clay. Seiring dengan meningkatnya permintaan pasar menjadi masalah tersendiri yang dialami mitra dikarenakan proses produksi masih manual dan pengelolaan manajemen usaha yang dilakukan mitra belum memanfaatkan teknologi digital. Metode yang dilakukan pada pengabdian ini yaitu sosialisasi, persiapan, penanganan permasahalan produksi dengan pemberian hibah alat produksi, penanganan permasalahan manajemen dengan memberikan pelatihan manajemen usaha berbasis digital. Pemberian hibah alat produksi telah dilaksanakan, dengan alat produksi baru jumlah produksi produk mitra meningkat hingga 10 kali lipat. Kegiatan pelatihan menajemen usaha telah dilaksanakan, mitra mampu dan berkomitmen menerapkan pencatatan keuangan pada media elektronik. Kemampuan mitra dalam menguasai meteri pelatihan tata kelola manajemen usaha berbasis elektronik sangat baik dengan nilai 86 sehingga diharapkan manajemen usaha semakin baik.
\end{abstract}

Kata kunci : Handcraft, Clay, oleh-oleh, produksi, manajement

\begin{abstract}
Clay is high artistic value handcraft that is easily shaped by hand. Ni Ketut Indrawati, S.sn (Partners) as an art activist is trying to explore the potential in the creative industry of Balinese souvenirs by creating interesting souvenirs, having Balinese specialties and at affordable prices. Partners made a flour-based handicraft innovation often referred to as Clay. Along with the increase in market demand, it becomes a problem experienced by partners because the production process is still manual and the management of the business undertaken by partners has not utilized digital technology. The method used in this service is socialization, preparation, handling production issues by granting production equipment grants, handling management problems by providing digital-based business management training. The granting of production equipment grants has been carried out, with new production equipment the number of production of partner products has increased 10 times. Business management training activities have been carried out, Mitra are able and committed to applying financial records to electronic media. The ability of partners in mastering electronic-based business management training methods is very good with a value of 86 so that it is expected that business management will get better.
\end{abstract}

Key words: Handcraft, Clay, souvenirs, production, management 


\section{PENDAHULUAN}

Terpilihnya Pulau Bali sebagai salah satu tempat wisata yang paling diminati oleh dunia menjadikan Bali sangat ramai dikunjungi oleh para wisatawan baik dari dalam dan luar negeri. Situasi dimana turis berlibur dan saat bertolak pulang pastinya berkeinginan membawa oleh - oleh daerah Bali sebagai kenangan liburan atau buah tangan untuk kerabat. Maka dari itu, banyak bermunculan toko oleh - oleh yang menjual berbagai macam souvenir khas bali. (Utama, 2017)

Akibat meningkatnya permintaan pasar oleh - oleh khas Bali hal ini menggerakan Mitra $\mathrm{Ni}$ Ketut Indrawati,S.Sn sebagai penggiat seni untuk menggali potensi pada bidang industri kreatif oleh-oleh khas Bali dengan produk yang menarik, produk yang memiliki khas Bali dan dengan harga yang terjangkau. Mitra melakukan inovasi kerajinan tangan berbahan dasar tepung yang sering di sebut dengan Clay. Clay adalah handcraft (kerajinan tangan) bernilai seni tinggi yang mudah dibentuk dengan tangan. Tepung yang biasanya digunakan untuk membuat adonan roti ini Mitra jadikan sebuah bentuk yang unik dan layak jual.

Mitra, dengan tangan terampilnya, memulai produksi dengan mengolah adonan dan membentuk clay menjadi produk - produk unik khas Bali seperti Gantungan kunci, Bingkai foto dan Magnet kulkas seperti ditunjukkan pada gambar 1. Seiring dengan meningkatknya permintaan pasar menjadi masalah tersendiri yang dialami mitra dikarenakan proses produksi yang masih manual hanya menggunakan tangan untuk membentuk sebuah produk di samping itu inovasi akan desain-desain produk baru harus dilakukan mengingat persaingan semakin ketat di pasaran. Pengelolaan manajemen usaha yang dilakukan mitra masih dengan cara konfensional belum memanfaatkan teknologi digital untuk mempermudah dalam melakukan manajemen usaha seperti melakukan pencatatan bahan baku, pencatatan stok, pencatatan keuangan. (Arnawa Dkk, 2018)

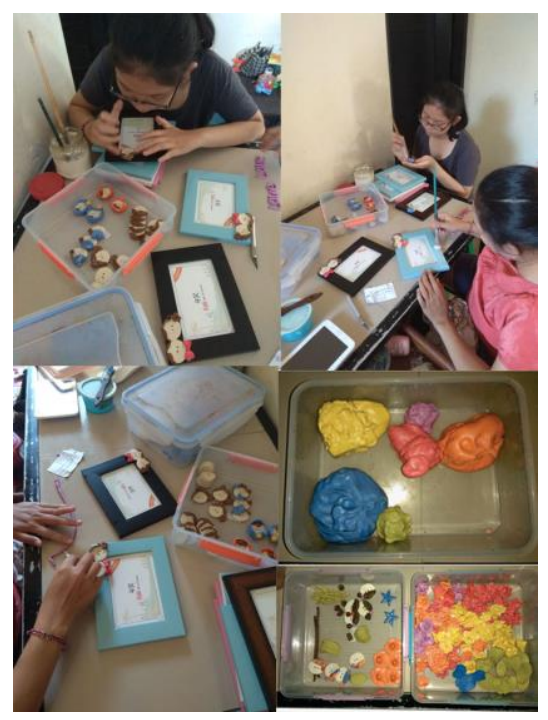

Gambar 1. Produksi Mitra

Berdasarkan hal tersebut adapun permalasahan prioritas yang dihadapi oleh mitra dan disepakati untuk diselesaikan yaitu: Proses produksi masih tradisional dengan menggunakan peralatan seadanya sehingga jumlah produksi tidak dapat memenuhi permintaan, desain produk masih sedikit, kurangnya pemanfaatan teknologi digital dalam mengelola manajemen usaha. Aktivitas produksi mitra seperti ditunjukkan pada Gambar 1. Solusi yang diberikan yaitu dengan memberikan hibah dan pendampingan pemanfaatan alat bantu produksi yang memadai, memberikan desain dan alat cetak berbagai bentuk produk yang inovatif, pengembangan desain produk baru, memberikan pelatihan manajemen usaha berbasis digital sehingga tata kelola usaha menjadi lebih terkontrol. (Nata \& Pande, 2020)

\section{RUMUSAN MASALAH}

Permasalahan mitra mengacu pada analisis situasi sebagai berikut:

1. Dalam proses produksi (membentuk desain sebuah produk) Mitra masih sepenuhnya menggunakan tangan sehingga jumlah produksi terbatas dan 
belum mampu memenuhi permintaan pasar.

2. Peralatan produksi dan desain produk mitra masih sedikit.

3. Mitra belum memanfaatkan teknologi untuk mempermudah dalam melakukan manajemen usaha seperti melakukan pencatatan bahan baku, pecatatan stok produk, pencatatan keuangan dan pesanan

\section{METODE}

Dalam pengabdian ini berbagi langkah telah disusun untuk menyelesaikan kegiatan pengabidan dengan baik dan lancar:

1. Sosialisasi

Sosialisasi kepada mitra mengenai rencana kegiatan serta menggali informasi dan data - data dari mitra guna untuk memetakan permasalahan secara mendalam.

\section{Persiapan}

Tahapan persiapan meliputi persiapan rencana kerja, persiapan peralatan yang diperlukan dan pembelian alat - alat hibah.

\section{Penanganan Permasalahan Produksi}

Permasalahan produksi yang dialami mitra adalah alat produksi yang masih tradisional sehinga jumlah produksi tidak dapat memenuhi permintaan, untuk itu pemberian hibah alat produksi berupa (1). Paket cetakan besi berbagai bentuk dan ukuran untuk proses pecentakan clay lebih cepat. (2). Keranjang ukuran besar untuk menyimpan bahan baku. (3). Rolling pin untuk menggiling adonan clay. (4). Toples untuk menyimpan bahan baku kedap udara. (5). Paket pisau kerajinan untuk finishing dan pembentukan hiasan. (6). Kuas cat ukuran besar dan kecil untuk proses finishing produk. (7). Tupperware untuk menyimpan adonan clay. (8). Memberikan pelatihan dan pendampingan menggunakan alat hibah .

4. Penanganan permasalahan manajemen

Memberikan pelatihan dan pendampingan manajemen usaha berbasis digital untuk melakukan pencatatan bahan baku, pecatatan stok produk, pencatatan keuangan dan pesanan dengan memanfaatkan media elektronik. Dengan target mitra menerapkan tata kelola usaha yang baik agara usaha semakin berkembang.

5. Evaluasi pelaksanaan program

Evaluasi merupakan tahapan untuk mengetahui sampai sejauh mana program yang direncanakan mencapai target atau sasaran yang diinginkan serta melihat kendala dan permasalahan yang mungkin terjadi selama keberlangsungan program.(Purwono P, 2015) Untuk menjamin dan mengantisipasi bila ada kendala, maka secara berkala akan dilakukan evaluasi terhadap program yang dijalankan sebanyak 1 kali dalam sebulan untuk mengoptimalkan setiap pelatihan, pelaksanaan dan implementasinya.

\section{PEMBAHASAN}

Kegiatan dilakukan sesuai dengan yang sudah direncanakan sebagi berikut :

\section{Sosialisasi dan persiapan}

Pelaksanaan pengambian diawali dengan sosialisasi dan persiapan dilakukan pada tanggal 4 Januari 2020, kegiatan ini bertujuan untuk menggali permasalahan pada mitra dan mendiskusikan solusi agar solusi yang diberikan tepat guna.

\section{Pemberian hibah}

Pemberian hibah alat - alat pendukung produksi produk mitra dan dilanjutkan dengan pelatihan pengoprasian alat produksi baru dilaksanakan pada tanggal 7 Januari 2020.

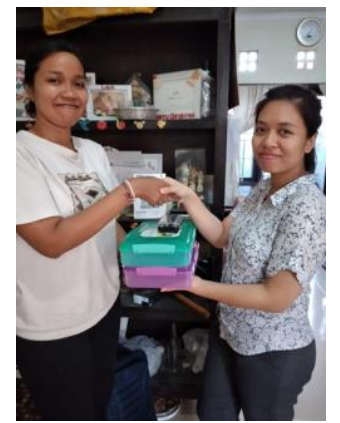

Gambar 2. Penyerahan hibah alat bantu produksi.adsas 
Setelah penyerahan hibah alat produksi, selanjutnya dilaksanakan pelatihan pengoprasian alat produksi baru yang dilaksanakan pada tanggal 14 Januari 2020.

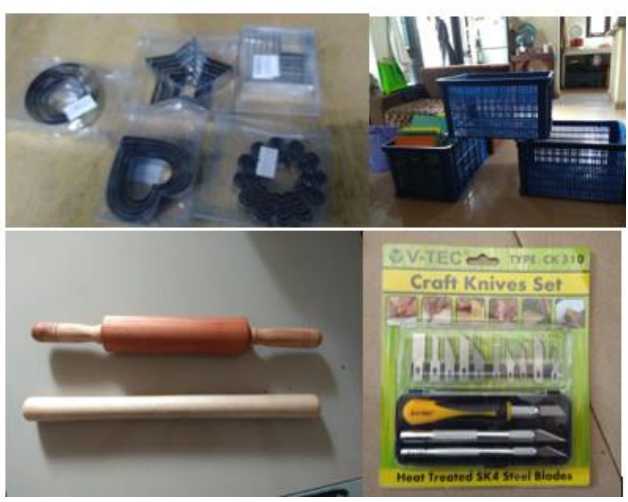

Gambar 3. Hibah alat produksi

Penyerahan hibah alat produksi berupa : (1). Paket cetakan besi berbagai bentuk dan ukuran untuk proses pecentakan clay lebih cepat. (2). Keranjang ukuran besar untuk menyimpan bahan baku. (3). Rolling pin untuk menggiling adonan clay. (4). Toples untuk menyimpan bahan baku kedap udara. (5). Paket pisau kerajinan untuk finishing dan pembentukan hiasan. (6). Kuas cat ukuran besar dan kecil untuk proses finishing produk. (7). Tupperware untuk menyimpan adonan clay.

\section{Pelatihan}

Sebagai kegiatan lanjutan yang sudah direncanakan sebelumnya. Setelah penyerahan hibah alat bantu produksi serta pelatihan dan pengenalan alat bantu produksi baru selanjutnya dilaksanakan pelatihan manajemen usaha (pencatatan dan pengelolaan bahan baku, pencatatan stok produk, pencatatan keuangan pada media elektronik). Kegiatan pelatihan manajemen usaha dilakukan secara daring pada tanggal 16 Juni 2020. Sebagai luaran dari kegiatan ini mitra mampu berkomitmen menerapkan pencatatan dan pengelolaan bahan baku, pencatatan stok produk, pencatatan keuangan pada media elektronik agar lebih mudah di kontrol sehingga manajemen usaha semakin baik.

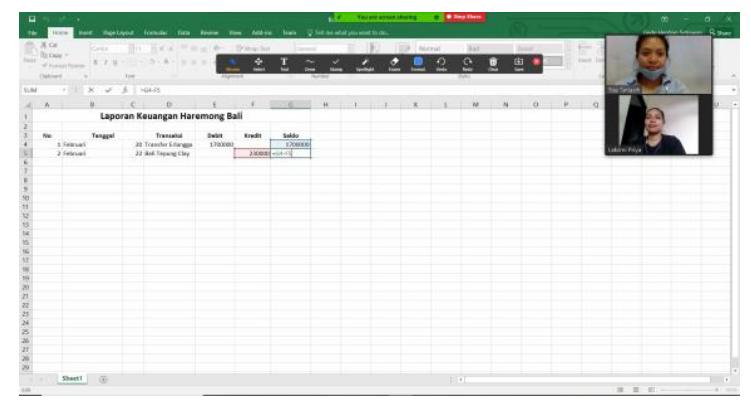

Gambar 4. Pelatihan Manajemen Usaha
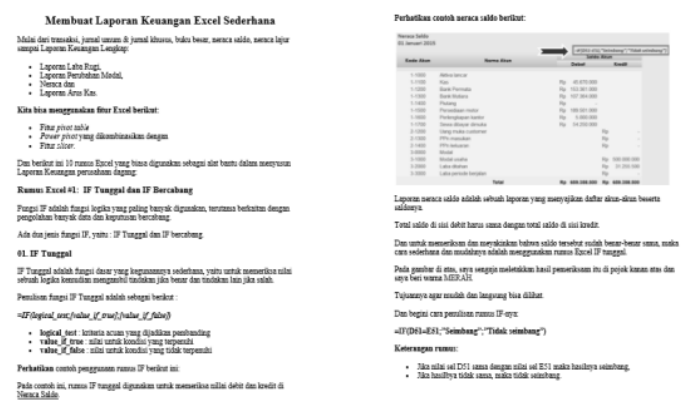

Gambar 5. Modul Pelatihan Keuangan Sederhana

\section{Evaluasi}

Berdasarkan hasil wawancara mitra setelah melaksanakan pemberian hibah alat produksi baru dan melakukan pelatihan penggunaan alat produksi baru, jumlah produksi meningkat setiap harinya. berdasarkan frekuensi cetak satu buah desain clay yang semula menghasilkan 1 buah produk siap finish, dengan bertambahnya jumlah alat cetak yang di hibahkan, hal ini mempercepat dan meningkatkan jumlah produksi hingga 10 buah produk dalam sekali proses cetak. Ditambah lagi dengan ditambahnya alat bantu finishing seperti pisau kerajinan dan kuas cat, proses finishing bisa dilakukan dengan lebih cepat dengan menambah tenaga khusus proses finishing.

Tabel 1. Pengukuran perbandingan produksi

\begin{tabular}{|c|c|c|c|c|}
\hline \multirow{2}{*}{$\begin{array}{c}\text { Pengujian } \\
\text { ke : }\end{array}$} & \multirow{2}{*}{$\begin{array}{c}\text { Frekuensi } \\
\text { Cetak }\end{array}$} & $\begin{array}{c}\text { Cetakan } \\
\text { lama }\end{array}$ & $\begin{array}{c}\text { Cetakan } \\
\text { baru }\end{array}$ & \multirow{2}{*}{$\begin{array}{c}\text { Heningkatan } \\
\text { hasil }\end{array}$} \\
\hline 1 & 1 & 1 & 10 & 10 Kali lipat \\
\hline 2 & 2 & 2 & 20 & 10 Kali lipat \\
\hline 3 & 3 & 3 & 30 & 10 Kali lipat \\
\hline
\end{tabular}


Tabel 2. Pengukuran perbandingan finishing

\begin{tabular}{|c|c|c|c|c|}
\hline \multirow{2}{*}{$\begin{array}{c}\text { Pengujian } \\
\text { ke : }\end{array}$} & Jumlah & \multicolumn{2}{|c|}{ Hasil Finish } & Peningkatan \\
\cline { 3 - 4 } & Bahan & Sebelum & Sesudah & (\%) \\
\hline 1 & 10 & 40 menit & 15 menit & $62.50 \%$ \\
\hline 2 & 20 & 80 menit & 40 menit & $50 \%$ \\
\hline 3 & 30 & 120 menit & 70 menit & $41.67 \%$ \\
\hline
\end{tabular}

Tabel 3. Pengukuran pelatihan manajemen

\begin{tabular}{|c|c|c|c|}
\hline No & \multicolumn{2}{|c|}{ Instrumen Pengujian } & Nilai \\
\hline 1 & \multicolumn{2}{|c|}{ Kemampuan pencatatan bahan baku } & 85 \\
\hline 2 & \multicolumn{2}{|c|}{ Kemampuan pencatatan stok produk } & 90 \\
\hline 3 & \multicolumn{2}{|c|}{ Kemampuan pencatatan keuangan sederhana } & 85 \\
\hline \multicolumn{3}{|c|}{ Rata-rata } & 86 \\
\hline \multicolumn{4}{|c|}{ Tabel 4. Keterangan penilaian } \\
\hline \multicolumn{2}{|r|}{ Interval Nilai } & \multicolumn{2}{|c|}{ Keterangan } \\
\hline \multicolumn{2}{|r|}{$86-100$} & \multicolumn{2}{|c|}{ Sangat Baik } \\
\hline \multicolumn{2}{|r|}{$70-85$} & \multicolumn{2}{|c|}{ Baik } \\
\hline \multicolumn{2}{|r|}{$55-69$} & \multicolumn{2}{|c|}{ Cukup } \\
\hline \multicolumn{2}{|r|}{$<54$} & \multicolumn{2}{|c|}{ Kurang } \\
\hline
\end{tabular}

\section{SIMPULAN}

Secara menyeluruh kesimpulan pelaksanaan pengabdian ini sebagai berikut :

1. Pemberian hibah alat produksi dapat membantu mitra dalam mempercepat proses produksi, sebelum mendapat alat hibah mitra hanya mampu menghasilkan 1 produk dalam sekali cetak namun saat ini dengan dibantu alat produksi baru mitra berhasil menghasilkan 10 buah produk siap finish dalam sekali cetak. Dengan demikian peningkatan produksi meningkat 10 kali lipat.

2. Pelatihan manajemen usaha (pencatatan dan pengelolaan bahan baku, pencatatan stok produk, pencatatan keuangan pada media elektronik) telah dilaksanakan. Mitra mampu dan berkomitmen menerapkan pencatatan keuangan pada media elektronik. Kemampuan mitra dalam menguasai meteri pelatihan tata kelola manajemen usaha berbasis elektronik sangat baik dengan nilai rata-rata 86 sehingga diharapkan manajemen usaha semakin baik.

\section{DAFTAR PUSTAKA}

Arnawa, I. B. K. S., Adnyana, I. M. B., \& Kumara, I. G. B. I. (2019). Pemanfaatan Teknologi Informasi Untuk Media Pemasaran Pada IRT Jajan Tradisional Bali. WIDYABHAKTI Jurnal Ilmiah Populer, 2(1), 31-36.

Nata, G. N. M., \& Pande, P. Y (2019). IRT Donat Kentang Dusun Samping Gianyar. WIDYABHAKTI Jurnal Ilmiah Populer, 2(2): 69-75

I Gusti Ngurah Rai Utama, 2017 "Integrasi Daya Tarik Wisata Kota Denpasar Bali”, Jurnal perkotaan Vol 9 No 1

Yulianto Purwono P., Dkk, 2015 "Evaluasi dan Pemetaan Potensi Desa Mitra DPPM UII", Jurnal Inovasi dan Kewirausahaan Vol. 4 No. 1 